Article

\title{
Early-Age Performance of Graphene-Nanoplatelet-Modified High-Strength Concrete Cured by Electric Thermal Curing in Severe Cold Regions
}

\author{
Zheng Zhou 1,2,3, Boyi Zhang 1,2,3,*, Mingzhi Wang ${ }^{1,2,3}$ and Wei Wang ${ }^{1,2,3}$ \\ 1 School of Civil Engineering, Harbin Institute of Technology, Harbin 150090, China; \\ 18b933035@stu.hit.edu.cn (Z.Z.); mwang@hit.edu.cn (M.W.); wwang@hit.edu.cn (W.W.) \\ 2 Key Lab of Structures Dynamic Behavior and Control of the Ministry of Education, Harbin Institute of \\ Technology, Harbin 150090, China \\ 3 Key Lab of Smart Prevention and Mitigation of Civil Engineering Disasters of the Ministry of Industry and \\ Information Technology, Harbin Institute of Technology, Harbin 150090, China \\ * Correspondence: zhangby@hit.edu.cn; Tel.: +86-4518-628-1118
}

check for

updates

Citation: Zhou, Z.; Zhang, B.;

Wang, M.; Wang, W. Early-Age

Performance of Graphene-

Nanoplatelet-Modified

High-Strength Concrete Cured by

Electric Thermal Curing in Severe

Cold Regions. Buildings 2022, 12, 86.

https:// doi.org/10.3390/

buildings12020086

Academic Editors: Shengwen Tang and Lei Wang

Received: 20 December 2021

Accepted: 7 January 2022

Published: 18 January 2022

Publisher's Note: MDPI stays neutral with regard to jurisdictional claims in published maps and institutional affiliations.

Copyright: (C) 2022 by the authors. Licensee MDPI, Basel, Switzerland. This article is an open access article distributed under the terms and conditions of the Creative Commons Attribution (CC BY) license (https:// creativecommons.org/licenses/by/ $4.0 /)$.

\begin{abstract}
Concrete structure construction with a high strength grade in cold regions is a significant problem that has elicited considerable research attention. In this work, we firstly prepared steel-fiberreinforced high-strength concrete (HSC) at $-20{ }^{\circ} \mathrm{C}$ for winter concrete construction in a cold region. Specifically, the combination of graphene nanoplatelet (GNP) incorporation and electric thermal (ET) curing could effectively improve the performance when preparing high-strength concrete (GNP-HSC) at $-20{ }^{\circ} \mathrm{C}$. The optimal amount of steel fiber added in this work was determined numerically and experimentally to be $2.5 \mathrm{vol} \%$. The temperature development regularity of the ET-cured sample was also recorded during the whole curing process. Mechanical property results indicated that the combination of GNP incorporation and ET curing could effectively stimulate the strength formation of HSC samples to $91.2 \mathrm{MPa}$ at early age, which is remarkable for concrete construction at $-20{ }^{\circ} \mathrm{C}$. Moreover, microstructural analyses (including XRD, TG and SEM analyses) were further conducted to verify the advantages of GNP incorporation and ET curing on the hydration products, hydration degree and microstructure of HSC samples. This work provides new insights into the application of GNP as a nanoscale material to improve the performance of HSC structures at extremely low temperatures.
\end{abstract}

Keywords: graphene nanoplatelets; electric thermal curing; reactive powder concrete; winter construction

\section{Introduction}

Reactive powder concrete (RPC) has become an innovative cement-based material over the last few decades. It has attracted broad attention from researchers worldwide due to its fine mechanical properties, high toughness and excellent durability [1-3]. The high strength of RPC closely corresponds to the particle density packing theory, and the utilization of fibers to reinforce the matrix and the addition of supplementary cementitious materials are also effective to improve the properties of RPC by densifying the composites and stimulating hydration inside the sample [3-6]. However, the application of RPC is largely restricted due to the complicated and strict curing conditions $[7,8]$, especially in cold regions for winter construction, where the harsh environment is not conducive to the replacement and operation of the required equipment. Specifically, winter concrete construction is a significant problem that largely restricts the economic and infrastructure development of many countries [9]. The main challenge is that cement-based materials fail to form strength under extremely low temperatures, due to the relatively rapidly occurring frost damage [10,11].

Previously, some curing methods have been presented to cure cement-based materials in a cold environment, such as thermal insulation curing and the warm shed construction method $[1,12,13]$. The main principle of these methods is the transfer of heat generated 
around concrete to the structure, or the direct heating of the concrete. These methods exhibit strong potential to prevent the concrete structure from incurring frost damage, leading to the increased strength of the structures $[14,15]$. However, these methods strongly rely on the environmental temperature, and the conditions cannot guarantee a continuous and stable curing temperature for the structure, which will lead to uncontrollable strength formation in the structure under subzero temperatures [16]. Therefore, a novel curing method is essential for RPC construction in cold regions.

Recently, electric thermal (ET) curing has been presented to achieve the strength formation of cement-based materials at various environmental conditions [17-19]. In particular, ET curing utilizes the heat generated from an electric current passing through the conductive cement-based materials [20], and the generated heat is expected to provide the required temperature to improve the strength of RPC at an early age under subzero temperatures. Under these circumstances, the early-age strength development regularity of ET-cured samples needs to be clarified; high strength at an early age under subzero temperatures is essential for concrete construction in cold regions because it can shorten the construction period and reduce the total cost of the construction. However, the later strength development of the ET-cured sample also requires investigation, i.e., when the environmental conditions become warmer, because the later strength development determines the ultimate mechanical properties and durability of the structure. Good late-stage strength development is crucial for construction in cold regions [12]. Therefore, it is necessary to investigate the effect of ET curing on the strength development of the structure.

Low and steady electrical conductivity for ET-cured samples is important to ensure the ongoing curing process. Steel fibers, as a traditional reinforcement filler with good electrical conductivity, have been proven to effectively enhance the mechanical properties, especially the toughness, of cement-based materials [21,22]. Therefore, the utilization of steel fibers as a reinforcement filler inside ET-cured HSC is reasonable. Moreover, graphene nanoplatelets (GNPs) are a nanoscale material with excellent electrical conductivity that can provide superior mechanical properties in cement-based materials [23]. Under these circumstances, the specific effect of GNP on the performance evolution of HSC structures prepared by ET curing needs to be thoroughly identified.

Above all, the question of how to rapidly stimulate the strength formation of RPC structures with excellent performance at low temperatures in order to meet the construction requirements in cold regions is now attracting considerable interest. This research focused on high-strength concrete construction in cold regions. In this work, GNP was incorporated into the sample to prepare a high-strength concrete sample (GNP-HSC), and ET curing was utilized to prepare GNP-HSC at $-20{ }^{\circ} \mathrm{C}$. Steel fibers were used as a reinforcement conductive filler inside the sample, and the percolation threshold of the steel fiber was determined numerically and experimentally. The temperature development of the ET-cured HSC sample at $-20^{\circ} \mathrm{C}$ was experimentally assessed. The early-age mechanical properties of GNP-HSC samples in different curing conditions were investigated. Moreover, the corresponding strength development of the sample was also studied and the evolution of the hydration products, hydration degree and microstructure of the samples was further researched.

\section{Materials and Methods}

\subsection{Materials}

In this study, 42.5 Ordinary Portland cement (OPC), in accordance with Chinese standard GB175-2007, was used as the main cementitious material; the detailed chemical composition of the cement is listed in Table 1. Silica fume was utilized as a supplementary cementitious material. The chemical composition of the used silica fume (SF) is shown in Table 2. The fine aggregate was fine silica sand with the diameter range of $0.84-2 \mathrm{~mm}$. Steel fibers with a length of $13.0 \mathrm{~mm}$ and diameter of $0.2 \mathrm{~mm}$ were added to serve as the electrically conductive filler, and the tensile strength of the fiber was $2850 \mathrm{MPa}$. GNPs with the average diameter of 2-5 $\mu \mathrm{m}$ and thickness of 5-10 $\mathrm{nm}$ were further incorporated into the sample, and the electrical resistivity of GNP was $9.2 \mathrm{~m} \Omega \cdot \mathrm{cm}$. The poly-carboxylate-based 
superplasticizer (SP) produced by HIT-QIANG SHI Concrete Technology Development Co., Ltd. was utilized to adjust the flowability of the fresh composite.

Table 1. Chemical composition of the cement.

\begin{tabular}{ccccccc}
\hline Oxide Species & $\mathrm{SiO}_{2}$ & $\mathrm{Al}_{2} \mathbf{O}_{3}$ & $\mathrm{Fe}_{\mathbf{2}} \mathrm{O}_{3}$ & $\mathrm{MgO}$ & $\mathbf{C a O}$ & $\mathrm{SO}_{3}$ \\
\hline Oxide content $(\mathrm{wt} \%)$ & 20.86 & 5.47 & 3.94 & 1.73 & 62.23 & 2.66 \\
\hline
\end{tabular}

Table 2. Chemical composition of the silica fume.

\begin{tabular}{cccccccc}
\hline Oxide Species & $\mathrm{CaO}$ & $\mathrm{SiO}_{2}$ & $\mathrm{Al}_{2} \mathrm{O}_{3}$ & $\mathrm{MgO}$ & $\mathrm{K}_{2} \mathrm{O}$ & $\mathrm{Na}_{2} \mathrm{O}$ & $\mathrm{Fe}_{2} \mathrm{O}_{3}$ \\
\hline Content $(\mathrm{wt} \%)$ & 0.63 & 87.67 & 0.28 & 3.41 & 1.2 & 4.12 & 0.60 \\
\hline
\end{tabular}

\subsection{Preparation of GNP-Modified Steel-Fiber-Reinforced High-Strength Concrete (GNP-HSC)}

The preparation procedure of GNP-HSC is shown in Figure 1. In particular, GNP, cement, silica fume and fine quartz sand were initially stirred in the stirring pot for $4 \mathrm{~min}$ to produce a uniform blend. Then, a solution of fresh water and SP was poured into the mixture for $5 \mathrm{~min}$. Steel fibers were incorporated into the mixture when the mixture reached a good flowability. Another 6 min of mixing was conducted to ensure a stable and homogeneous fresh composite of GNP-HSC. Finally, the GNP-HSC mixture was cast into a cuboid mold with a size of $40 \times 40 \times 160 \mathrm{~mm}$, and two $60 \times 40 \mathrm{~mm}$ copper electrodes were inserted inside the mold $140 \mathrm{~mm}$ apart. The initial resistivities of seven mixtures incorporated with various content of steel fibers from 0 to $3 \mathrm{vol} \%$ were prepared to experimentally determine the optimal content of steel fibers, and detailed mixture proportions are listed in Table 3. For all samples, the ratio of water to binder was kept at 0.2 , and the ratio of binder to sand was 1:1. The additive amount of GNP was determined to be 0.5 and $1.0 \mathrm{vol} \%$. The content of steel fibers added was chosen according to the volume ratio of the sample, and the proportions of GNP were used as the volume ratio regarding cement paste.

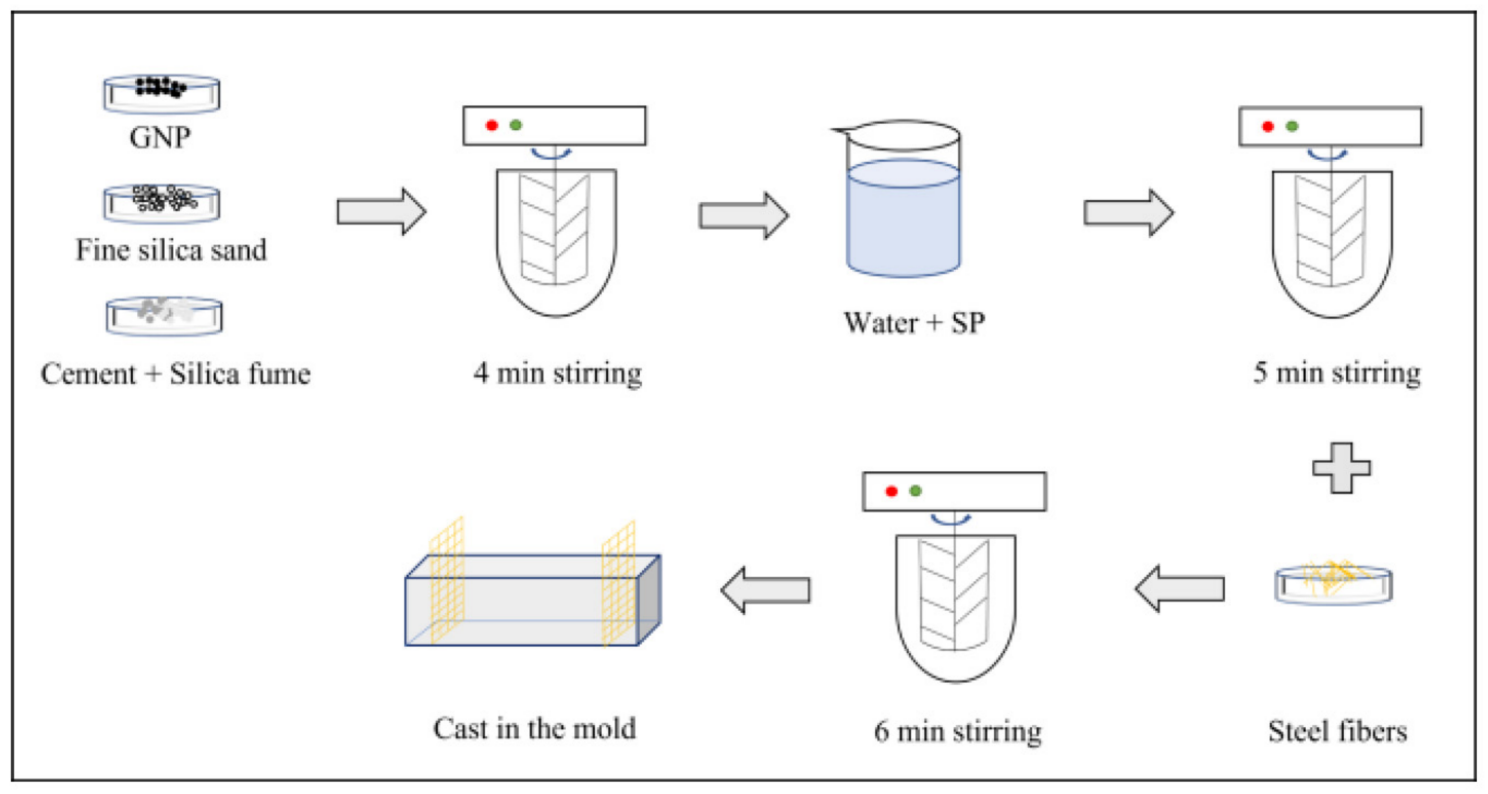

Figure 1. Fabrication process of GNP-HSC samples. 
Table 3. Mixing proportions of HSC.

\begin{tabular}{|c|c|c|c|c|c|}
\hline $\begin{array}{l}\text { Cement } \\
\left(\mathrm{kg} / \mathrm{m}^{3}\right)\end{array}$ & $\begin{array}{c}\text { Sand } \\
\left(\mathrm{kg} / \mathrm{m}^{3}\right)\end{array}$ & $w / b$ & $\begin{array}{l}\text { Silica Fume } \\
\left(\mathrm{kg} / \mathrm{m}^{3}\right)\end{array}$ & $\begin{array}{l}\text { Steel Fiber } \\
\text { (vol\%) }\end{array}$ & SP $(w t \%)$ \\
\hline 1171 & 1404 & 0.2 & 234 & 0 & 1 \\
\hline 1171 & 1404 & 0.2 & 234 & 0.5 & 1.5 \\
\hline 1171 & 1404 & 0.2 & 234 & 1 & 2 \\
\hline 1171 & 1404 & 0.2 & 234 & 1.5 & 2 \\
\hline 1171 & 1404 & 0.2 & 234 & 2 & 2.5 \\
\hline 1171 & 1404 & 0.2 & 234 & 2.5 & 2.5 \\
\hline 1171 & 1404 & 0.2 & 234 & 3 & 3 \\
\hline
\end{tabular}

\subsection{Resistivity Measurement}

The measurement procedure of the initial resistivity is shown in Figure 2. The twoelectrode method was used to measure the resistance of the samples with the TH2811D digital multimeter produced by Tonghui Electronics Co., Ltd. The resistivity of the samples was calculated by Equation (1).

$$
\rho=\frac{S R}{L}
$$

in which $\rho$ is the resistivity, while $S$ and $R$ represent the cross-sectional area and resistance of the sample, respectively. $L$ represents the distance between the electrodes.

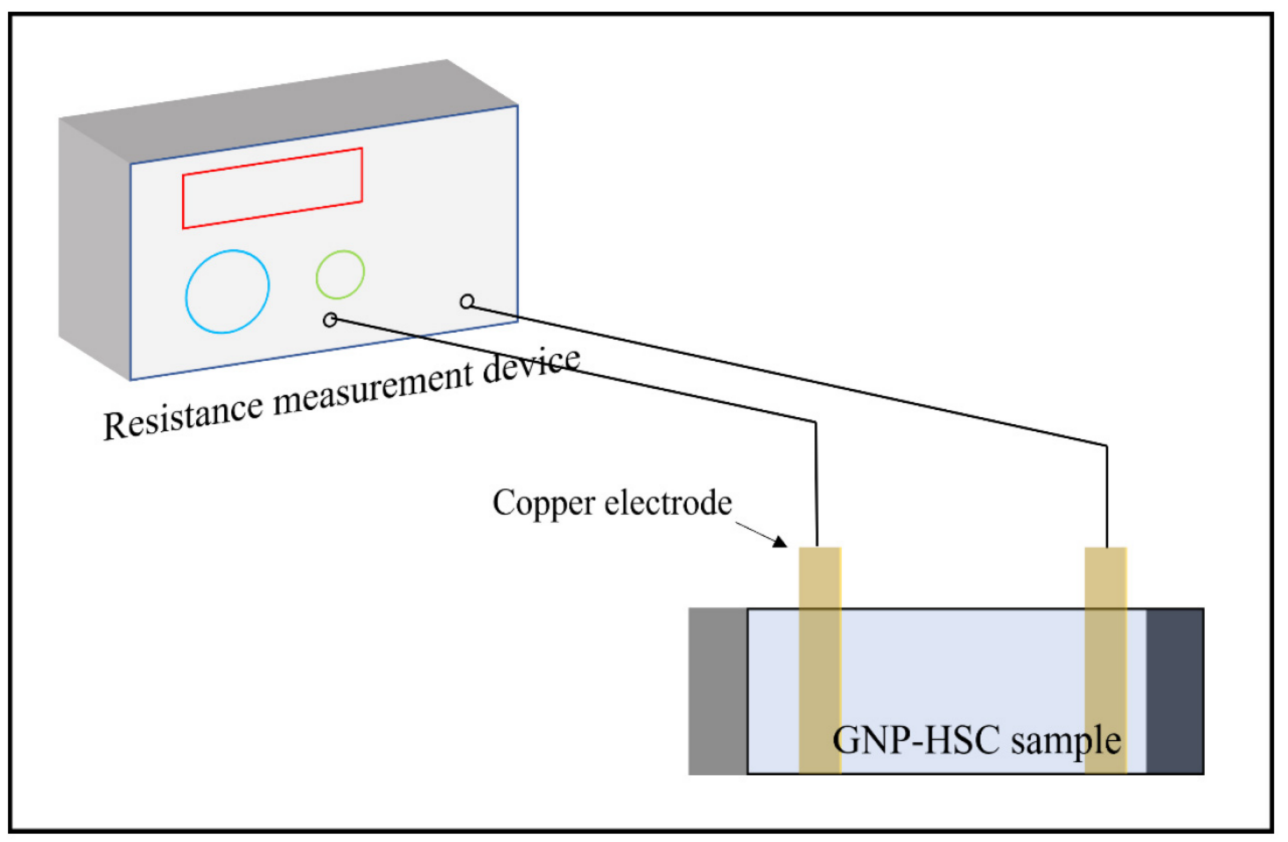

Figure 2. Diagram of resistance measurement procedure.

\subsection{Curing Regimes}

In this work, the GNP-HSC sample was cured by ET curing at $-20^{\circ} \mathrm{C}$ for $12 \mathrm{~h}$ and then the sample was subjected to room-temperature (RT) curing for another $36 \mathrm{~h}$ to investigate the effect of ET curing on the strength evolution of the samples. Two-day RT curing was also employed to highlight the effect of ET curing on the mechanical properties of GNP-HSC samples, and the microstructure of 2-day RT-cured samples was further compared with that of the samples cured by ET curing.

\subsection{Electric Thermal (ET) Curing of GNP-HSC}

A detailed diagram of the temperature monitoring and specific ET curing is depicted in Figure 3. Specifically, the fresh mixture was placed in a refrigerator with an automatic temperature control system to simulate the ultra-low temperature environment of $-20^{\circ} \mathrm{C}$. 
The GNP-HSC sample was placed into the refrigerator once the casting was finished, and the AC voltage was immediately applied to the fresh sample to ensure the generation of the electric current. Additionally, the thermocouple connected to the multi-channel temperature measurement system was inserted into the center of the sample to record the temperature development of GNP-HSC samples cured by ET curing, and the temperature development was recorded every $30 \mathrm{~min}$.

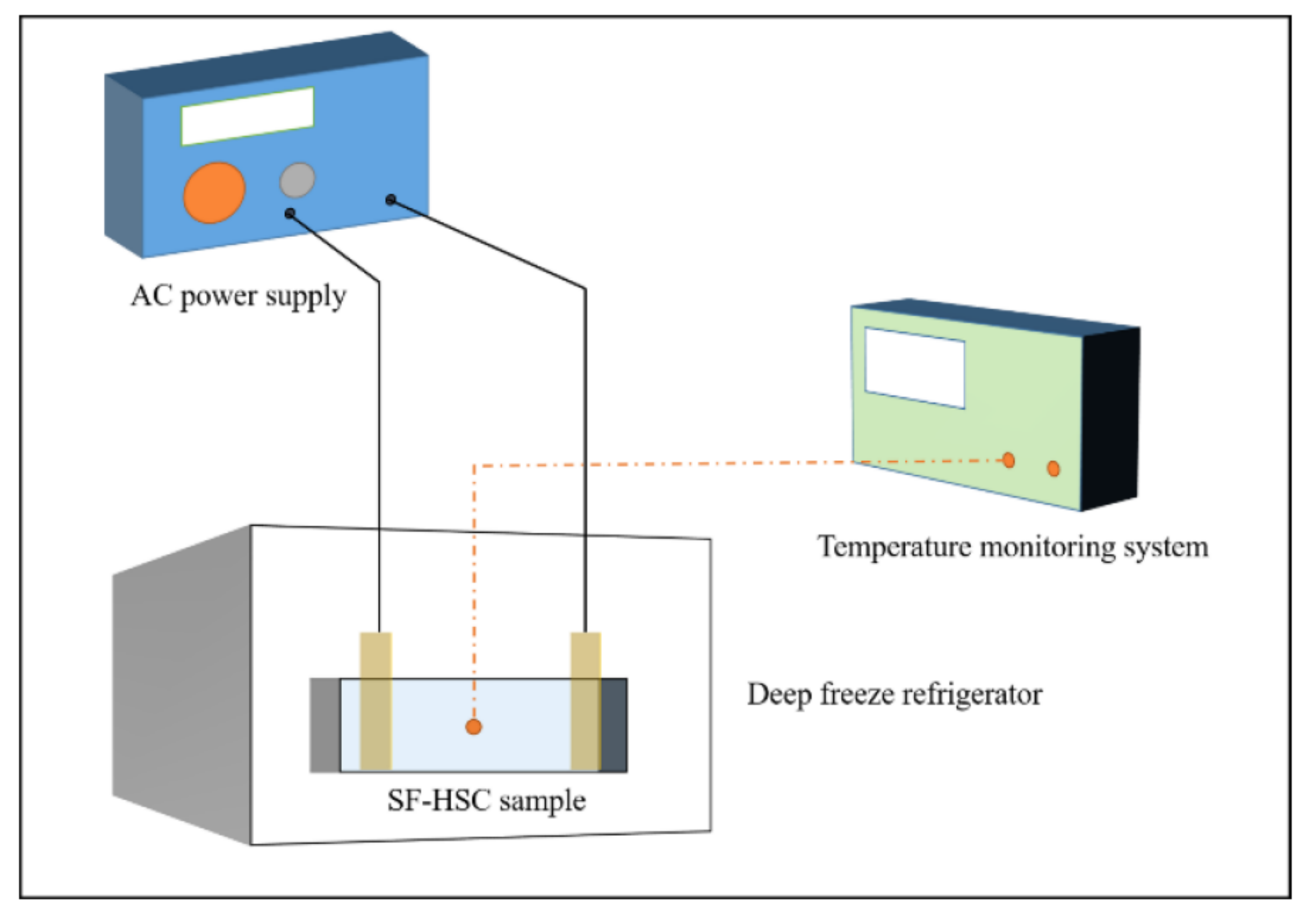

Figure 3. ET curing and temperature monitoring of GNP-HSC.

The whole ET curing process can be divided into two parts. Firstly, the velocity of heat generation in the sample is higher than that of the heat release, leading to strong heat exchange between the hot sample and the cold environment; then, this exchange behavior will finally terminate due to the balance between the heat generation and the release of heat with the ongoing ET curing process. At this time, the power of heat generation also meets a balance with the power of heat release, resulting in a constant curing temperature in the sample. In this work, electric heat generated from the effect of the alternative current was the main source of heat generation for the sample; thus, the electric resistance value of the GNP-HSC sample was measured every $30 \mathrm{~min}$ to ensure a stable electric power supply with the value of $30 \mathrm{~W}$ during the process of ET curing. The detailed calculation equation is as follows:

$$
\mathrm{P}=\frac{S U^{2}}{\rho L}
$$

in which $\mathrm{P}$ is the electric power and $U$ is the applied voltage of ET curing; detailed explanations of other parameters have been introduced in Section 2.3.

\subsection{Characterization}

The compressive strength of the GNP-HSC samples was measured with the loading rate of $2.4 \mathrm{kN} / \mathrm{s}$ with Chinese Standard GB/T 17671-1999 (according to ASTM C 349 [24]). The flexural strength measurements were conducted via the three-point bending test with the loading rate of $0.05 \mathrm{kN} / \mathrm{s}$. The tested samples were broken into pieces with a diameter of 3-5 $\mathrm{mm}$ and placed into anhydrous ethanol to stop the hydration process for further microstructure analyses. X-ray diffraction (XRD) patterns of GNP-HSC samples were recorded on an $X^{\prime}$ pert PRO diffractometer within the scanning $2 \theta$ range of $5^{\circ}-50^{\circ}$. 
TG analysis was conducted with a TG instrument (STA449F3, Netzsch Company, Selb, Germany) to obtain the thermo-gravimetric curves of the samples subjected to different regimes. The thermal tests were conducted at a heating rate of $10^{\circ} \mathrm{C} / \mathrm{min}$ from 50 to $800{ }^{\circ} \mathrm{C}$ under a nitrogen atmosphere, with a sample mass of approximately $10 \mathrm{mg}$.

\subsection{Percolation Analysis}

The optimal addition amount of steel fiber was initially determined by a numerical simulation based on the APMS program [25]. The particle sizes of cement and silica fume are much smaller than those of fine silica sand and steel fiber. Therefore, a mesoscale numerical model containing steel fiber and fine silica sand was established to investigate the percolation behavior of steel fibers inside the sample. A digitized sample with the size of $120 \times 120 \times 120 \mu^{3}$ was initially constructed, and this size was greater than the representative elementary volume (REV) of the sample [26]. Then, fine silica sand particles were randomly thrown inside the empty domain until the domain was filled with the particles. The fibers were further placed into the sample without overlapping behavior. Finally, the percolation analysis was conducted based on the APMS percolation program to estimate the percolation threshold of the steel fiber network, leading to the determination of the optimal addition amount of steel fibers to ensure the ideal electric conductivity behavior [27]. The mathematic relationships between the volume ratio of steel fibers and the connected fiber fraction were defined as in Equations (3) and (4).

$$
\begin{gathered}
y=\frac{\sum_{k=1}^{c} V_{k}}{\sum_{i=1}^{n} V_{i}} \\
x=\frac{\sum_{i=1}^{n} V_{i}}{V_{s}}
\end{gathered}
$$

in which $x$ is the volumetric ratio of the steel fibers and the sample, $y$ represents the connected fraction of steel fibers, $V_{i}$ is the volume of the individual steel fiber, $V_{S}$ represents the volume of the particle sample and $n$ is the total amount of the incorporated steel fibers. The volume of the connected steel fiber cluster and the total amount of the connected steel fiber cluster are represented by $V_{k}$ and $c$, respectively. When $y$ is equal to 1 , this indicates that the full connected network is constructed inside the sample.

\section{Results}

\subsection{Numerical and Experimental Investigation of Optimal Amount of Steel Fiber Addition}

It is important to ensure the steady and low resistivity of the sample during the ET curing process. The initial resistivity of cement-based materials may exhibit a relatively low value due to the existence of a high-content pore solution, while it will experience an obvious increase because the ongoing hydration process will consume large amounts of water. Based on a previous study, the incorporation of conductive fillers is beneficial for constructing a stable conductive network inside the sample in order to maintain the stability of the electrical resistivity of the sample [19]. Therefore, percolation analysis of steel fibers was conducted to determine the optimal addition amount of steel fibers as the main conductive filler. The results of the numerical simulation are shown in Figure 4. Figure 4a exhibits the spatial distribution situation of fine silica sand. Random sequential addition was conducted and the spatial distribution of steel fibers without an overlapping phenomenon is shown Figure $4 \mathrm{~b}$. Figure $4 \mathrm{c}$ demonstrates the synergistical distribution of fine silica sand and steel fibers. The percolation threshold result is displayed in Figure $4 \mathrm{~d}$, and a detailed explanation of the $y$-axis and $x$-axis is provided in Section 2.7. It can be seen from Figure $4 \mathrm{~d}$ that the percolation threshold determined by the numerical simulation of steel fibers is within the range of $1.75 \sim 2.5 \mathrm{vol} \%$. Moreover, experiments were also conducted to verify the accuracy of the numerical simulation and further determine the optimal addition of steel fibers, and the addition of steel fibers was prepared as listed in Table 3. Figure $4 \mathrm{e}$ depicts the initial resistivities of the samples with various degrees of 
steel fiber addition. It can be observed from Figure 4e that the initial resistivity exhibited a decreasing trend with the increase in steel fiber content. The resistivity of the sample with no addition of steel fibers reached up to $412 \Omega \cdot \mathrm{cm}$, which is not suitable for the implementation of ET curing. When the steel fiber content increased to $2.5 \mathrm{vol} \%$, the initial resistivity of the sample decreased to $78 \Omega \cdot \mathrm{cm}$, and with the further increase in the steel fiber content, the resistivity of the GNP-HSC sample exhibits little change. This indicates that a fully connected network of steel fibers was constructed inside the GNP-HSC sample. It is remarkable that the percolation threshold of steel fibers obtained from experiments corresponds well with the calculated range of $1.5 \sim 2.5 \mathrm{vol} \%$ of steel fibers from the numerical simulation results. Based on this, the optimal addition amount of steel fibers inside the GNP-HSC samples was determined to be $2.5 \mathrm{vol} \%$ numerically and experimentally.
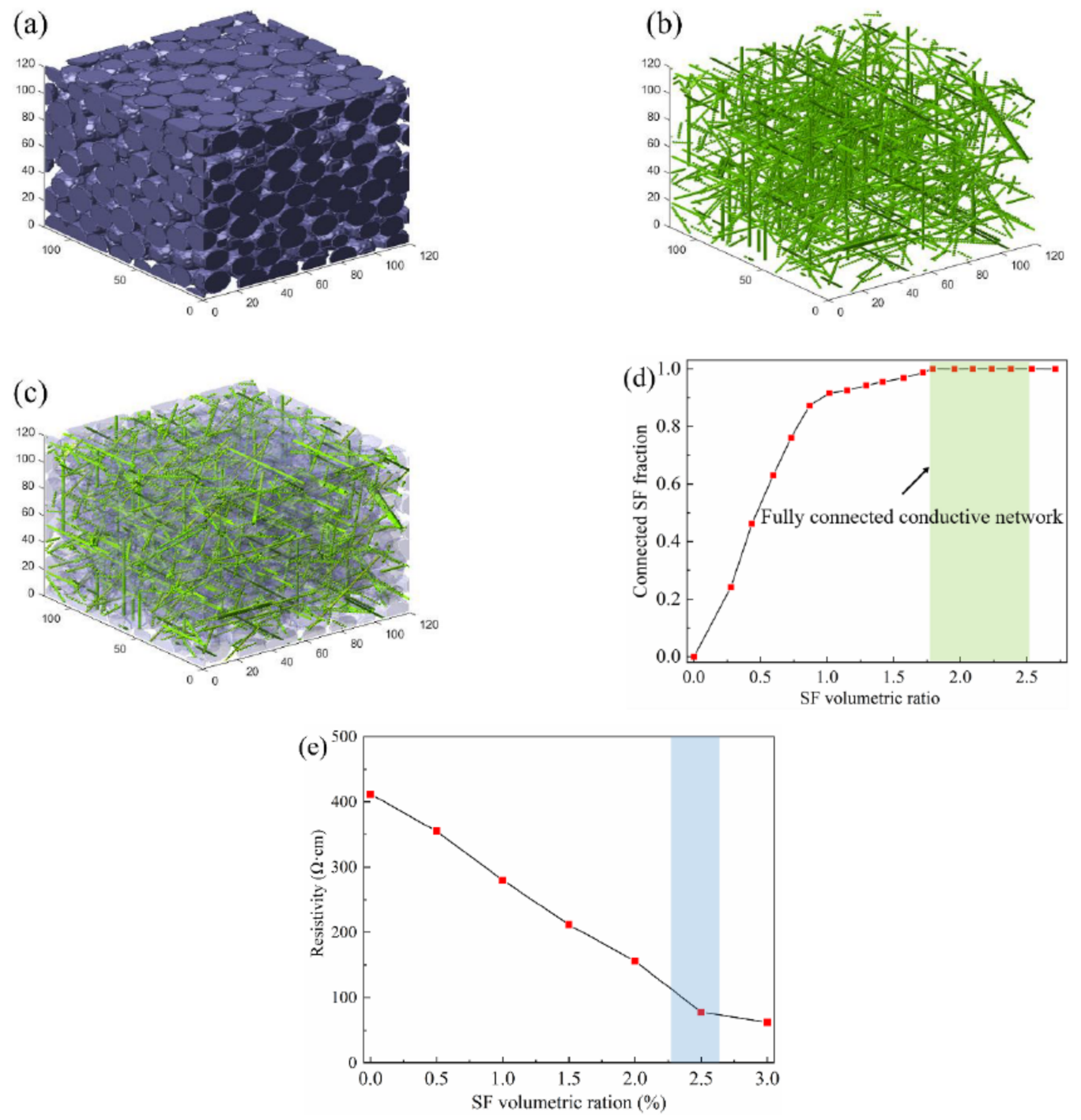

Figure 4. Numerical simulation results: (a) the fine silica sand particle model; (b) digitized steel fibers added to the sample; (c) the digitized steel fibers added to the sample along with the particle microstructure; (d) the percolation analysis results of the connected steel fibers and (e) resistivity of the samples with various amounts of steel fiber content.

\subsection{Temperature Evolution of GNP-HSC Cured by ET Curing}

The typical curve of temperature development of the ET-cured sample with $1 \mathrm{vol} \%$ GNP addition at $-20^{\circ} \mathrm{C}$, recorded experimentally, is depicted in Figure 5. It can be noticed from Figure 5 that with the supplied electric power of $20 \mathrm{~W}$, the curing temperature of the GNP-HSC sample with $1.0 \mathrm{vol} \%$ GNP can reach up to $75^{\circ} \mathrm{C}$ during the $12 \mathrm{~h}$ ET curing 
process. In addition, the curing temperature is mainly concentrated within the range of $63 \sim 67{ }^{\circ} \mathrm{C}$ during ET curing process, which is beneficial for the strength formation of GNP-HSC samples. In conclusion, the temperature development of the sample cured by ET curing at $-20{ }^{\circ} \mathrm{C}$ indicates the stability of electrical conductivity during the curing process, highlighting the potential of ET curing as a high-temperature curing method for HSC construction in cold regions.

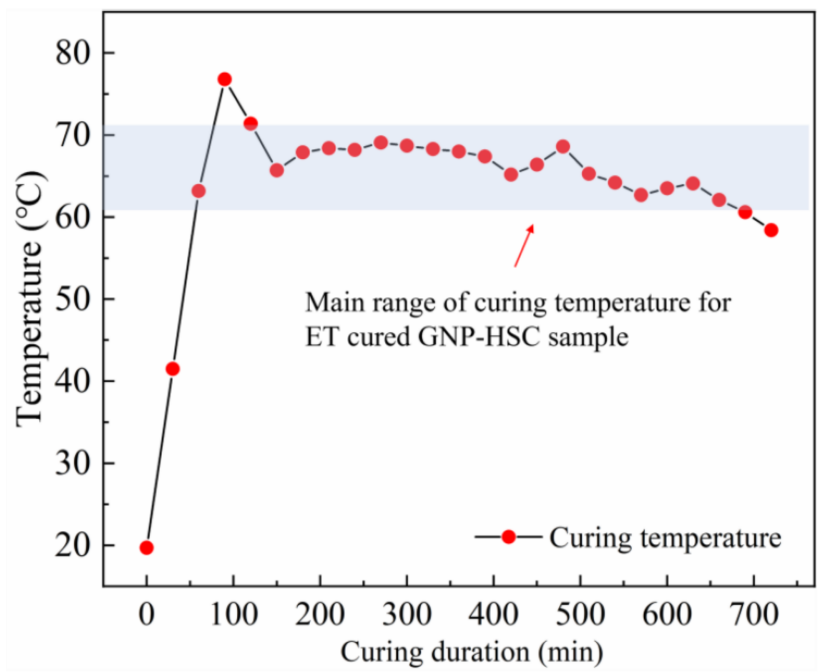

Figure 5. Temperature development of ET-cured GNP-HSC with 1 vol\% GNP addition.

\subsection{Mechanical Properties}

The compressive strength results of GNP-HSC samples subjected to various curing conditions are exhibited in Figure 6a. It can be seen that the GNP-HSC sample cured by $12 \mathrm{~h}$ ET curing and $36 \mathrm{~h}$ RT curing exhibits higher compressive strength regardless of the amount of GNP added. In particular, the compressive strength of the GNP0-HSC sample cured by $12 \mathrm{~h}$ ET curing and $36 \mathrm{~h}$ RT curing reached up to $78.5 \mathrm{MPa}$, experiencing an obvious increase (27.2\%) in comparison with that of the GNP0-HSC sample cured by 2-day RT curing (61.7 MPa). Further, the incorporation of GNP can also improve the compressive strength of the samples. The compressive strengths of the ET-cured GNP0.5-HSC and GNP1.0-HSC samples subjected to $12 \mathrm{~h}$ ET and $36 \mathrm{~h}$ RT curing were 85.6 and $91.2 \mathrm{MPa}$, respectively. These values are $9.0 \%$ and $16.2 \%$ higher than that of the sample with no GNP incorporation. The enhancement effect of GNP can also be observed in the samples cured by 2-day RT curing, as shown in Figure 6a. The flexural strengths of the samples subjected to various curing conditions develop in the same regularity as the compressive strength and are shown in Figure 6b. As depicted in Figure 6b, the flexural strength of the GNP0-HSC sample cured by 2-day RT curing reached $10.5 \mathrm{MPa}$, and early-age ET curing at $-20{ }^{\circ} \mathrm{C}$ can effectively improve the flexural strength by $30.5 \%$ up to $13.7 \mathrm{MPa}$. Moreover, the flexural strengths of the samples were greatly enhanced with the addition of GNP. The flexural strengths of ET-cured samples with 0.5 and $1.0 \mathrm{vol} \%$ GNP addition reached up to 14.5 and 15.1 MPa, respectively.

The mechanical property results highlight the advantage of the combination of earlyage ET curing and GNP incorporation for improving the early-age performance of GNPHSC samples at $-20^{\circ} \mathrm{C}$. The implementation of ET curing as a self-heating curing method can ensure the strength formation of concrete structures in extremely cold environments, and the incorporation of GNP can further stimulate the strength development of the samples. This highlights the potential of the implementation of GNP-HSC structure construction at subzero temperatures in cold regions. 

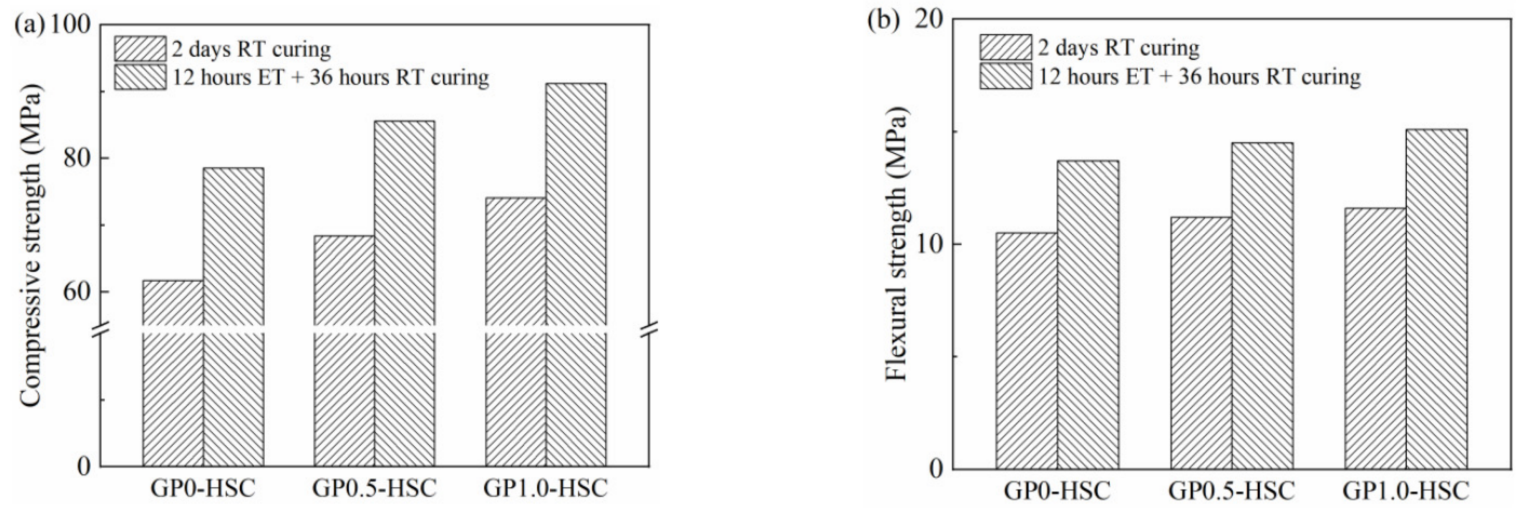

Figure 6. Mechanical properties of GNP-HSC samples cured by different curing regimes: (a) Compressive strength and (b) flexural strength.

\subsection{Hydration Products of GNP-HSC Samples}

\subsubsection{XRD Analysis}

The XRD patterns of GNP-HSC samples cured by ET curing and 2-day RT curing with different amounts of GNP content were obtained to identify the phase composition of hydrated samples, as shown in Figure 7. It can be observed from Figure 7 that the clinker inside the samples can react with the water to form C-S-H gel and portlandite, and the silica fume can partly react with portlandite to form extra C-S-H [28,29]. The existing phases of the GNP-HSC samples (mainly including alite $\left(\mathrm{C}_{3} \mathrm{~S}\right), \mathrm{Ca}(\mathrm{OH})_{2}$, Belite $\left(\mathrm{C}_{2} \mathrm{~S}\right)$ and $\left(\mathrm{CaCO}_{3}\right)$ ) are almost the same, and this indicates that the hydration reaction inside the samples subjected to different curing conditions is consistent. Moreover, a large amount of C3S can be observed inside the sample because of the characteristic of cementitious materials with a low water content $[30,31]$. The strength of the cementitious materials mainly relies on the hydration effect of $\mathrm{C} 3 \mathrm{~S}$ at an early age, because it can intensively react with water to produce $\mathrm{CH}$ at the early age of hydration. As demonstrated in Figure 7, the samples subjected to early-age ET curing possess a higher $\mathrm{CH}$ peak level compared with that of the sample cured by 2-day RT curing with the same amount of GNP added, indicating the more thorough hydration reaction inside the ET-cured GNP-HSC samples. Further, the samples with GNP incorporation also exhibit a higher $\mathrm{CH}$ level under the same curing method, indicating the advantage of GNP incorporation for improving the hydration effect inside the sample. The XRD analysis results further highlight the importance of ET curing and GNP incorporation to improve the hydration degree of GNP-HSC samples under extremely low temperatures.

\subsubsection{TG Analysis}

The thermal analysis results of the GNP-HSC samples cured by 2-day RT curing and early-age ET curing with different GNP amounts are shown in Figure 8a,b, respectively. Additionally, the differential thermogravigram (DTG) curve was obtained by the firstorder differential treatment of the TG curve and is exhibited in the patterns. It is effective to utilize the DTG curve to identify different heat absorption peaks corresponding to different thermal decomposition phases inside the sample. TG analysis is an effective method to determine the content of hydration products such as C-S-H gel, ettringite (AFt) and crystalline portlandite $(\mathrm{CH})$. As depicted in Figure $8 \mathrm{~b}$, three dominating heat adsorption peaks can be observed in the DTG curves. The first peak at the temperature range of $80-120^{\circ} \mathrm{C}$ indicates the removal of bound water of C-S-H and $\mathrm{AFt}$, and the second peak located between 400 and $430{ }^{\circ} \mathrm{C}$ is induced by the decomposition of portlandite (CH) [32-34]; the third peak shown around $650{ }^{\circ} \mathrm{C}$ is considered to be evidence of the existence of $\mathrm{CaCO}_{3}$.

Further, detailed statistics of the $\mathrm{CH}$ and total weight losses for the samples subjected to different curing conditions are shown in Figure 9. It can be seen from Figure 9 that 
the implementation of ET curing could effectively improve the hydration degree of the samples compared with the RT curing method. Moreover, the incorporation of GNP can further enhance the hydration degree of HSC samples. In particular, the samples with increasing GNP content exhibit higher total weight loss regardless of the curing method, which is an indicator of the more thorough hydration reaction inside the sample (including the hydration of cement and the pozzolanic reaction of silica fume) [35]. In addition, the ET-cured sample with $1.0 \mathrm{vol} \%$ addition of GNP exhibits the highest total weight loss of $8.3 \%$, highlighting the advantage of GNP incorporation for the hydration degree inside ET-cured samples, and this is consistent with the XRD analysis result shown in Figure 7.

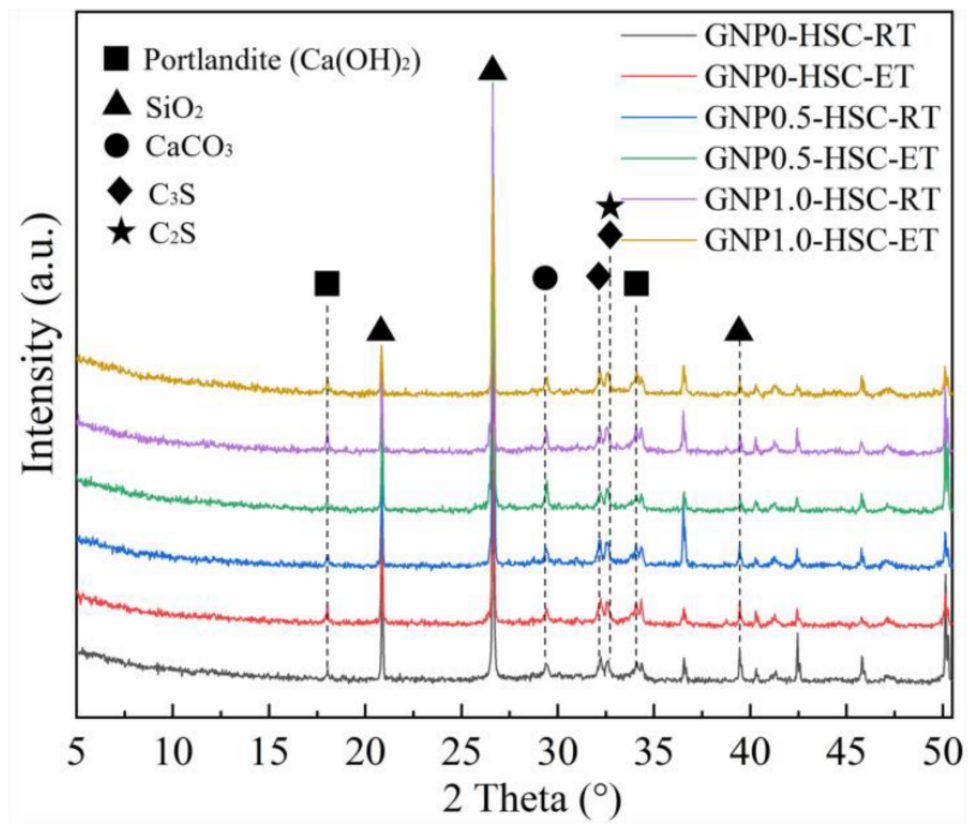

Figure 7. XRD patterns of GNP-HSC samples cured by different curing regimes.
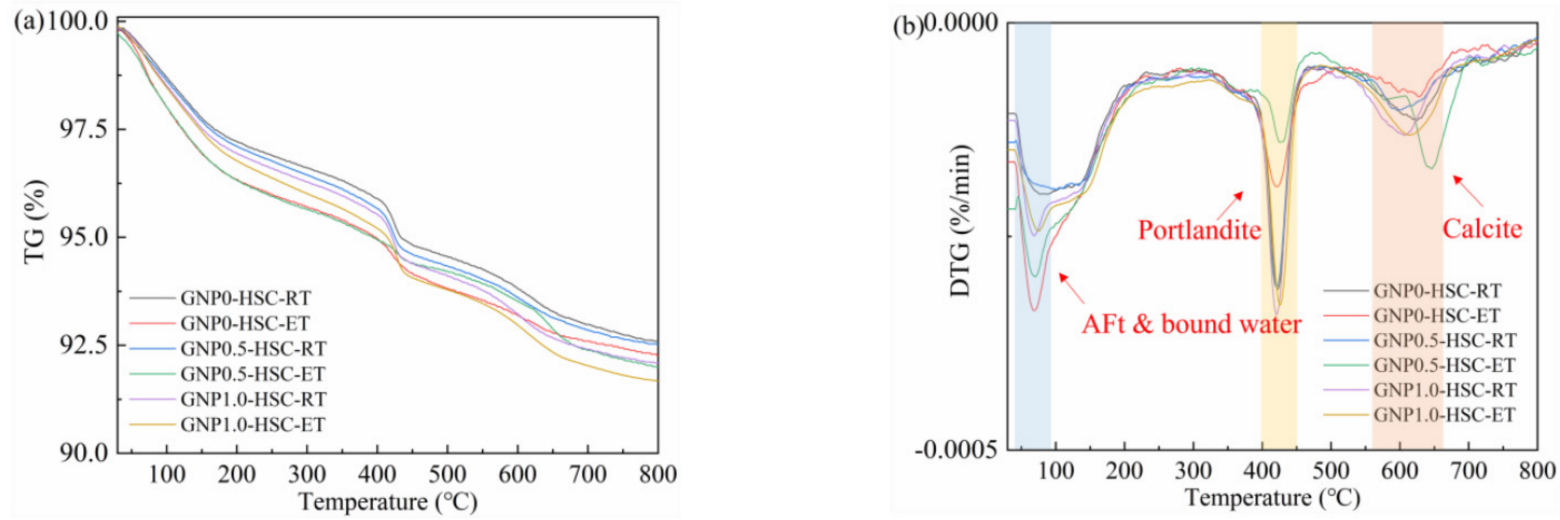

Figure 8. TG analysis of the GNP-HSC samples with different curing conditions: (a) TG analysis and (b) DTG analysis.

\subsection{SEM Analysis}

SEM analysis was conducted to investigate the microstructure of HF-HSC samples subjected to various methods. The corresponding images are shown in Figure 10. Specifically, Figure 10a exhibits the microstructure of the 3-day RT-cured sample, where the anchoring situation between the steel fiber and the matrix is poor, and an obvious crack can be observed in the interfacial transition zone around the fiber [36]. Nevertheless, the implementation of ET curing can effectively eliminate this adverse effect. The anchoring situation between the steel fiber and the matrix is well improved, as exhibited in Figure 10b. Moreover, hydration products show a trend to attach onto the steel fiber inside the ET-cured 
sample, as shown in Figure 10b, which is beneficial for improving the mechanical properties of GNP-HSC samples. Moreover, the incorporation of GNP inside the ET-cured sample is also beneficial for the performance of the samples. In particular, a dense microstructure can be observed in the ET-cured samples with 1 vol\% GNP addition, as depicted in Figure 10c-f. Moreover, it can be seen from Figure $10 \mathrm{~d}, \mathrm{f}$ that the hydration products also exhibit a trend to attach to the GNP as a conductive filler; it can be concluded from this phenomenon that GNPs can also serve as a nucleation site for hydration products, which is advantageous for improving the hydration degree of HSC samples [37].

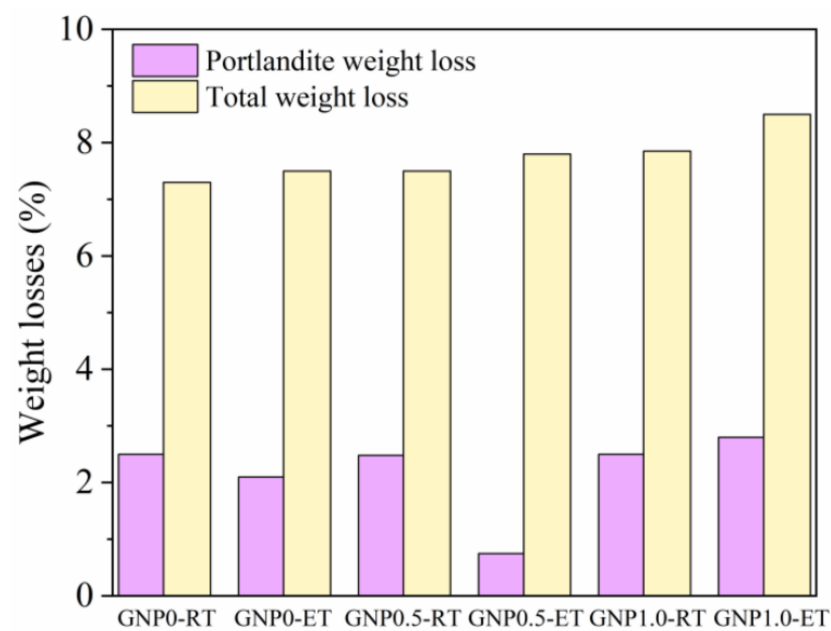

Figure 9. Detailed statistics of portlandite and total weight losses of the samples under different curing conditions.
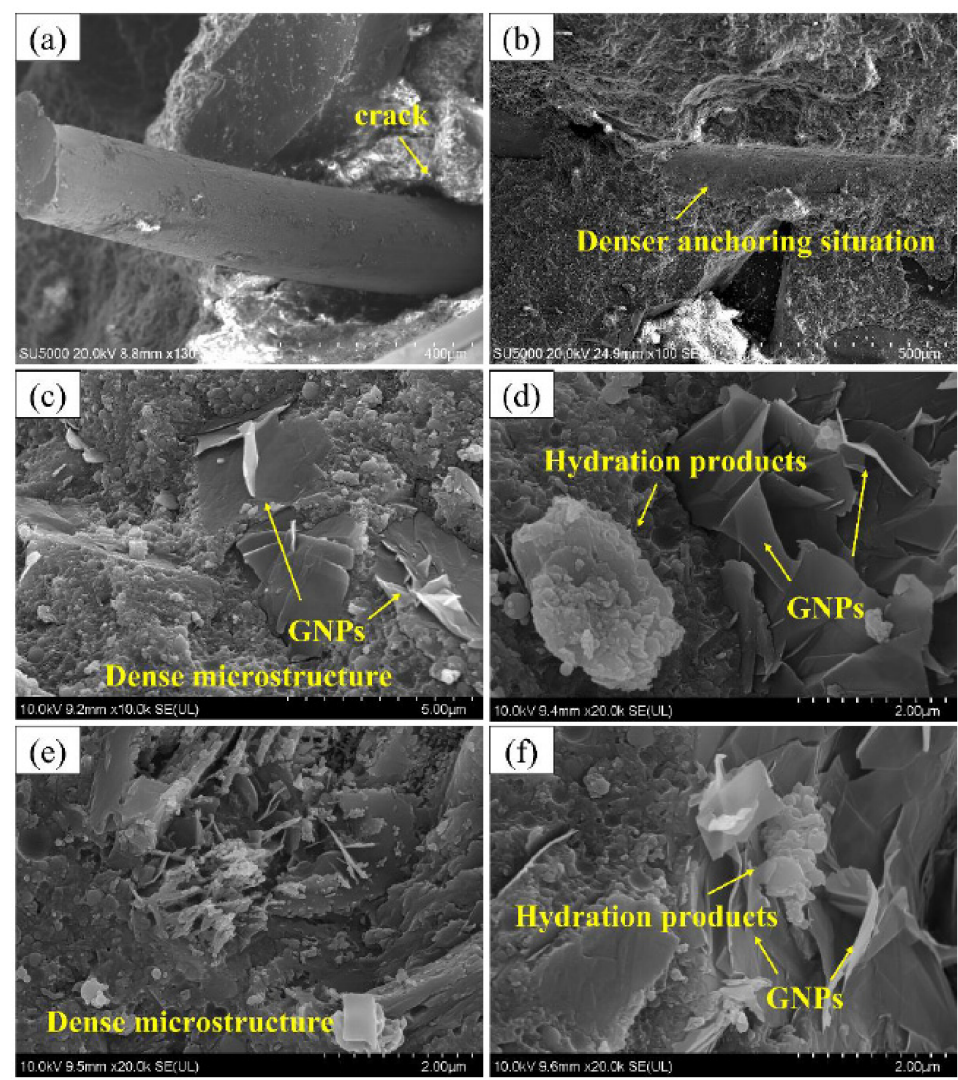

Figure 10. SEM morphologies of GNP-HSC samples cured by different methods: RT-cured samples with the magnification of (a) $130 \times$ and ET-cured sample with the magnification of (b) $100 \times$, (c) $10,000 \times$, (d) $20,000 \times$, (e) $20,000 \times$ and (f) $20,000 \times$. 


\section{Conclusions and Future Work}

In conclusion, GNP was utilized in this work to effectively improve the performance of ET-cured HSC samples at $-20{ }^{\circ} \mathrm{C}$. The optimal incorporation amount of steel fibers as the main conductive filler was initially determined numerically and experimentally. The temperature development of ET-cured HSC samples under $-20^{\circ} \mathrm{C}$ was also recorded. Moreover, the multi-scale properties of GNP-HSC samples were further investigated. The tentative conclusions are as follows:

(1) The optimal addition content of conductive steel fibers was numerically and experimentally determined to be $2.5 \mathrm{vol} \%$. The temperature development of HSC samples cured by ET curing under $-20{ }^{\circ} \mathrm{C}$ was recorded. The ET-cured samples exhibited great temperature development regularity and the curing temperature of the sample was maintained in the range of $60 \sim 70^{\circ} \mathrm{C}$.

(2) The incorporation of GNP could effectively enhance the mechanical properties of HSC samples. In particular, the compressive strengths of the $12 \mathrm{~h}$ ET-cured GNP0.5-HSC and GNP1.0-HSC samples, respectively, reached up to 85.6 and 91.2 MPa with further $36 \mathrm{~h}$ RT curing, which are $9.0 \%$ and $16.2 \%$ higher than that of the ET-cured sample with no GNP addition. Moreover, the implementation of ET curing is also advantageous for the performance of GNP-HSC samples: with the same GNP content added, ET-cured samples possessed higher mechanical properties than RT-cured samples.

(3) The results of the XRD, TG and SEM analyses suggest that the incorporation of GNP can stimulate the hydration reaction in ET-cured GNP-HSC samples with a higher hydration degree and denser microstructure, emphasizing the superiority of GNP incorporation for the performance of ET-cured samples for winter concrete construction in cold regions.

In this work, the combination of ET curing and GNP incorporation was adopted to promote the strength formation of GNP-HSC samples at $-20^{\circ} \mathrm{C}$, laying a solid foundation for high-strength concrete construction in cold regions. However, future studies should further investigate the specific effects of the multi-conditions of ET curing on the performance of highstrength concrete, such as curing temperature, curing duration and environmental temperature.

Author Contributions: Conceptualization, Z.Z.; methodology, Z.Z.; software, M.W.; validation, Z.Z. and B.Z.; formal analysis, Z.Z.; investigation, Z.Z.; resources, Z.Z.; data curation, B.Z.; writing—original draft preparation, Z.Z.; writing — review and editing, B.Z.; visualization, B.Z.; supervision, B.Z.; project administration, W.W. All authors have read and agreed to the published version of the manuscript.

Funding: This research received no external funding.

Data Availability Statement: The raw data used to support the findings of this study are available from the corresponding author upon request.

Conflicts of Interest: The authors declare no conflict of interest.

\section{References}

1. Nmai, C.K. Recent Advances in Ultra-high Performance Concrete. J. Korean Recycl. Constr. Resour. Inst. 2013, 1, 163-172. [CrossRef]

2. He, S.; Qiu, J.; Li, J.; Yang, E.H. Strain hardening ultra-high performance concrete (SHUHPC) incorporating CNF-coated polyethylene fibers. Cem. Concr. Res. 2017, 98, 50-60. [CrossRef]

3. Fan, D.Q.; Yu, R.; Shui, Z.H.; Wu, C.F.; Song, Q.L.; Liu, Z.J.; Sun, Y.; Gao, X.; He, Y.J. A new design approach of steel fibre reinforced ultra-high performance concrete composites: Experiments and modeling. Cem. Concr. Compos. 2020, 110, 103597. [CrossRef]

4. Shi, C.; Wu, Z.; Xiao, J.; Wang, D.; Huang, Z.; Fang, Z. A review on ultra high performance concrete: Part I. Raw materials and mixture design. Constr. Build. Mater. 2015, 101, 741-751. [CrossRef]

5. Ma, B.; Mei, J.; Tan, H.; Li, H.; Liu, X.; Jiang, W.; Zhang, T. Effect of Nano Silica on Hydration and Microstructure Characteristics of Cement High Volume Fly Ash System under Steam Curing. J. Wuhan Univ. Technol. Mater. Sci. Ed. 2019, 34, 604-613. [CrossRef]

6. Yazici, H.; Yardimci, M.Y.; Aydin, S.; Karabulut, A.Ş. Mechanical properties of reactive powder concrete containing mineral admixtures under different curing regimes. Constr. Build. Mater. 2009, 23, 1223-1231. [CrossRef]

7. Yazici, H.; Deniz, E.; Baradan, B. The effect of autoclave pressure, temperature and duration time on mechanical properties of reactive powder concrete. Constr. Build. Mater. 2013, 42, 53-63. [CrossRef] 
8. Kahanji, C.; Ali, F.; Nadjai, A.; Alam, N. Effect of curing temperature on the behaviour of UHPFRC at elevated temperatures. Constr. Build. Mater. 2018, 182, 670-681. [CrossRef]

9. Liu, J.; Li, Y.; Yang, Y.; Cui, Y. Effect of low temperature on hydration performance of the complex binder of silica fume-portland cement. J. Wuhan Univ. Technol. Mater. Sci. Ed. 2014, 29, 75-81. [CrossRef]

10. Polat, R.; Demirboğa, R.; Karakoç, M.B.; Türkmen, I. The influence of lightweight aggregate on the physico-mechanical properties of concrete exposed to freeze-thaw cycles. Cold Reg. Sci. Technol. 2010, 60, 51-56. [CrossRef]

11. Wang, L.; Fan, G.; Yang, H.; Wang, Y. Comparison of fly ash, PVA fiber, MgO and shrinkage-reducing admixture on the frost resistance of face slab concrete via pore structural and fractal analysis. Fractals 2021, 29, 2140002. [CrossRef]

12. ACI 306.1-90; Standard Specification for Cold Weather Concreting. American Concrete Institution: Farmington Hills, MI, USA, 2002; pp. 1-5.

13. ACICommittee 306 Cold Weather Concreting. In Proceedings of the American Concrete Institute; Elsevier Ltd.: Amsterdam, The Netherlands, 2010.

14. Kim, J.K.; Chu, I.Y.; Yi, S.T. Minimum curing time for preventing frost damage of early-age concrete. IES J. Part A Civ. Struct. Eng. 2008, 1, 209-217. [CrossRef]

15. Koh, K.T.; Ryu, G.S.; Lee, J.H. Effect of curing method on the strength development and freezing-thawing durability of the concrete incorporating high volume blast-furnace slag subjected to initial frost damage. Adv. Mater. Res. 2013, 602-604, 962-967. [CrossRef]

16. Barna, L.A.; Seman, P.M.; Korhonen, C.J. Energy-efficient approach to cold-weather concreting. J. Mater. Civ. Eng. 2011, 23, 1544-1551. [CrossRef]

17. Liu, Y.; Wang, M.; Wang, W. Ohmic heating curing of electrically conductive carbon nanofiber/cement-based composites to avoid frost damage under severely low temperature. Compos. Part A Appl. Sci. Manuf. 2018, 115, 236-246. [CrossRef]

18. Ziolkowski, M.; Kovtun, M. Confined-Direct Electric Curing of NaOH-activated fly ash based brick mixtures under free drainage conditions: Part 1. Factorial experimental design. Constr. Build. Mater. 2017, 155, 1050-1062. [CrossRef]

19. Tian, W.; Liu, Y.; Wang, W. Multi-structural evolution of conductive reactive powder concrete manufactured by enhanced ohmic heating curing. Cem. Concr. Compos. 2021, 123, 104199. [CrossRef]

20. Liu, Y.; Wang, M.; Wang, W. Electric induced curing of graphene/cement-based composites for structural strength formation in deep-freeze low temperature. Mater. Des. 2018, 160, 783-793. [CrossRef]

21. Garas, V.Y.; Kurtis, K.E.; Kahn, L.F. Creep of UHPC in tension and compression: Effect of thermal treatment. Cem. Concr. Compos. 2012, 34, 493-502. [CrossRef]

22. Rao, R.; Fu, J.; Chan, Y.; Tuan, C.Y.; Liu, C. Steel fiber confined graphite concrete for pavement deicing. Compos. Part B Eng. 2018, 155, 187-196. [CrossRef]

23. Jiang, L.; Liu, Z.; Yu, Y.; Ben, X. The effect of graphene on the conductivity of magnesium sulfate cement. Constr. Build. Mater 2021, 312, 125342. [CrossRef]

24. BS EN 12390-3; Testing Hardened Concrete Part 3: Compressive Strength of Test Specimens. British Standards Institution: London, UK, 2009.

25. Wang, M.; Al-Tabbaa, A.; Wang, W. Improving discrete particle packing models for the microstructural formation simulation of Portland cement. Constr. Build. Mater. 2019, 229, 116841. [CrossRef]

26. Al-Raoush, R.; Papadopoulos, A. Representative elementary volume analysis of porous media using X-ray computed tomography. Powder Technol. 2010, 200, 69-77. [CrossRef]

27. Wang, M.; Liu, Y.; Qi, B.; Al-Tabbaa, A.; Wang, W. Percolation and conductivity development of the rod networks within randomly packed porous media. Compos. Part B Eng. 2020, 187, 107837. [CrossRef]

28. Shen, P.; Lu, L.; He, Y.; Wang, F.; Hu, S. The effect of curing regimes on the mechanical properties, nano-mechanical properties and microstructure of ultra-high performance concrete. Cem. Concr. Res. 2019, 118, 1-13. [CrossRef]

29. Qin, L.; Gao, X. Recycling of waste autoclaved aerated concrete powder in Portland cement by accelerated carbonation. Waste Manag. 2019, 89, 254-264. [CrossRef] [PubMed]

30. Von Werder, J.; Simon, S.; Lehmann, C.; Selleng, C.; Fontana, P.; Meng, B. Autoclaving of ultra-high performance concrete (UHPC). Ce/Papers 2018, 2, 131-136. [CrossRef]

31. Huang, J.; Li, W.; Huang, D. Fractal analysis on pore structure and hydration of magnesium oxysulfate cements by first principle, thermodynamic and microstructure-based methods. Fractal Fract. 2021, 5, 164. [CrossRef]

32. Ma, S.; Li, W.; Zhang, S.; Hu, Y.; Shen, X. Study on the hydration and microstructure of Portland cement containing diethanolisopropanolamine. Cem. Concr. Res. 2015, 67, 122-130. [CrossRef]

33. Shao, Y.; Rostami, V.; He, Z.; Boyd, A.A. Accelerated carbonation of portland limestone cement. J. Mater. Civ. Eng. 2014, 26, 117-124. [CrossRef]

34. Fang, Y.; Chang, J. Microstructure changes of waste hydrated cement paste induced by accelerated carbonation. Constr. Build. Mater. 2015, 76, 360-365. [CrossRef]

35. Lei, W.; Luo, R.; Zhang, W.; Jin, M. Effects of fineness and content of phosphorus slag on cement hydration, permceability, pore structure and fractal dimension of concrete. Fractals 2021, 29, 2140004. [CrossRef]

36. Xiao, J.; Xu, Z.; Murong, Y.; Jiang, H.; Qu, W. Effect of chemical composition of fine aggregate on the frictional behavior of concrete-soil interface under sulfuric acid environment. Fractal Fract. 2022, 6, 22. [CrossRef]

37. Lei, W.; Zeng, X.; Yang, H.; Lv, X. Investigation and application of fractal theory in cement-based materials: A review. Fractal Fract. 2021, 5, 247. [CrossRef] 